\title{
Nuclear Stress Test
}

National Cancer Institute

\section{Source}

National Cancer Institute. Nuclear Stress Test. NCI Thesaurus. Code C80408.

A study using radioisotope tagged blood components and a nuclear scanning machine to monitor the blood flow to the myocardium during or immediately following exercise. 